\title{
Satellite Telephone
}

National Cancer Institute

\section{Source}

National Cancer Institute. Satellite Telephone. NCI Thesaurus. Code C60788.

A mobile phone that communicates directly with orbiting communications satellites.

Depending on the architecture of a particular system, coverage may include the entire Earth, or only specific regions. 